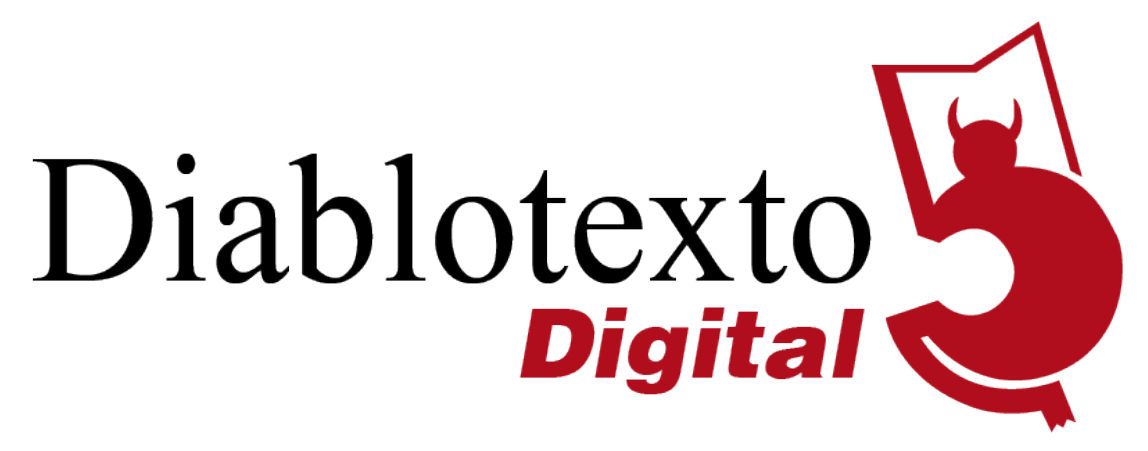

\title{
Mujeres 'transhemisféricas': Letras de España y América Latina en diálogo
}

\author{
MARIELA SÁNCHEZ \\ Universidad NACIONAL DE LA PLATA / CONICET
}

En las últimas dos décadas ha emergido, con frecuencia y renovados intentos de sistematización, la necesidad de reflexión sobre perspectivas que implican un determinado distanciamiento geográfico pero que, sobre todo, conllevan una problematización, para nada resuelta, de cruces culturales, conciencia de alteridad y divergencias en relación con todo atisbo de identidad unívoca y tranquilizadora. En general ha predominado y, de alguna manera, se ha instalado el término "transatlánticos" para adjetivar aquellos enfoques multidisciplinarios, pero con clara prevalencia de los estudios literariostendientes a considerar los intercambios, puntos de encuentro, alejamiento y divergencia que se producen entre una y otra margen atlántica. Sin menoscabo del concepto, es preciso subrayar que con esa elección se está tomando una parte por el todo, ya que suele producirse una focalización en Europa en relación con América y, muy marcadamente, con América del Norte. Por medio de esta observación y del encuadre general del presente monográfico, en modo alguno se desecha ni desestima la mencionada denominación, pues hay allí un campo sobre el cual seguir dialogando y que, más allá de acuerdos y desacuerdos en materia de disquisiciones teóricas frente a las que estas páginas no aspiran a dar cuenta de un acabado estado de la cuestión, pueden desplegarse adyacencias e incluso fricciones con acercamientos como los de 
los estudios poscoloniales y hasta con cruces que deben retrotraernos a contactos rastreables en el modernismo hispánico, todo lo cual invita a repensar discusiones no del todo saldadas y pasibles de mayor desarrollo. Hay que reconocer, además, que esa demarcación que con especial visibilidad se ha instalado a partir de una perspectiva como la de Julio Ortega, y que ha tenido sus respectivas especificaciones, entre otros, en estudiosos como Sebastiaan Faber (2008 y 2019), Abril Trigo (2012) y en una búsqueda de sistematización como la de Juan Antonio García Galindo (2014), ha alimentado debates que resuenan en reflexiones proferidas desde otras latitudes aún bastante desatendidas.

Sin embargo -y sin que implique una contradicción el hecho de que lo transatlántico se retome en los artículos aquí reunidos- se ha propuesto para este monográfico de Diablotexto Digital la adjetivación "transhemisféricas" para englobar una convocatoria que aspiró al tratamiento de la obra de mujeres que bien pueden estar en relación con la línea de investigación antes señalada pero que, a la luz de una conceptualización un tanto más abarcadora, habilitan la apertura hacia un panorama más multifocal, remitiendo a una metáfora óptica de una tecnología que siguió a la funcional pero difícil lógica de lo bifocal. Se trata de un panorama más extenso que el que, en términos estrictos, parece concentrarse en un solo tipo de cruce, susceptible de síntesis en el par EsteOeste.

Por otra parte, como se anticipaba, en el término "transatlántico" parece prevalecer una mirada que muchas veces se enfoca en el -y se emite a partir del- Norte. El neologismo "transhemisférico", considerado ya por Raquel Macciuci $(2018,2019)$ en materia de literatura española contemporánea en convivencia con el concepto de "transatlántico", apunta a subrayar la idea de un cruce que conlleva, en casi todas las mujeres cuyas obras, protagonismos y/o problemáticas se contemplan en este monográfico, al menos dos trayectorias hemisféricas: Este-Oeste y Norte-Sur.

Si se traspasa lo cartográfico, que en última instancia da cuenta de un distanciamiento entre otros posibles, ese doble cruce está también en consonancia con la idea de resaltar que, en el caso de las mujeres, son varios 
los distritos que se atraviesan, y que -aunque con un innegable incremento de concientización y significativos avances-, no se ha soltado del todo el lastre de preconceptos, exigencias, mandatos y situaciones que han interpelado con más vehemencia a las mujeres que a los hombres, y que suponen a menudo descolocación, descentramiento, estar fuera de lugar.

El monográfico número 8 de Diablotexto Digital presenta, en la sección Baza de textos: Estudios críticos, indagaciones que contemplan espacios de convergencias "transhemisféricas" en relación con la obra de mujeres en las que alguna dimensión de un cruce atlántico deviene una instancia significativa y hasta constitutiva de un proceso de creación o de actuación pública, en tanto mujeres vinculadas con alguna rama de la expresión literaria o artística.

Las mujeres que devienen objeto de análisis, o mejor, las mujeres cuya obra es considerada, son escritoras. La única excepción, en términos estrictos, está dada por el caso de Maruja Mallo, pero en el ensayo centrado en su obra compuesta entre dos espacios de pertenencia es especialmente pertinente el eje del monográfico y se evidencia un factor común con otros cruces explorados a lo largo del volumen, que incluso los condensa en otro lenguaje expresivo.

El ordenamiento de los artículos no responde del todo a una tradicional progresión cronológica. Si bien en parte del índice puede percibirse un avance en ese sentido, ya desde el inicio se plantea una cohesión que supone otro tipo de anclajes y una ilación de puntos de contacto para la organización general.

El monográfico se abre con el artículo de Silvia Cárcamo, de la Universidade Federal do Rio de Janeiro, al que me referiré con algo más de detenimiento pues presenta un panorama inicial en torno a desplazamientos de sujetos y experiencias de escritura propias de las últimas décadas. En el sentido de lo transatlántico, alude a los trabajos de Julio Ortega (2010), Ana Gallego Cuiñas (2012), Erika Martínez (2019) y Raquel Macciuci (2006); pero también retoma la alusión a la crítica que estudió a fondo las redes transhemisféricas del modernismo hispánico y su relevancia para abordar el tránsito entre Europa y América Latina, sin dejar de mencionar los cruces 
concernientes a otras latitudes. Esto se lleva a cabo con un metódico procedimiento que conduce a la focalización en contactos, en particular de los intelectuales, artistas y escritores del exilio español en América a partir de la derrota republicana en 1939. En cuanto a la investigación sobre Rosa Chacel, núcleo del artículo, junto con un especializado detenimiento en la autora a cuyo estudio Cárcamo se viene abocando en sucesivas pesquisas, implica un registro imprescindible no solo para avanzar en el conocimiento de la autora en cuestión sino también en lo que representó crear una literatura en un contexto extranjero, el encuentro de propios y ajenos, de mujeres pertenecientes a distintos estratos sociales, de mujeres separadas por una guerra, un exilio y una dictadura.

Luego de este primer estudio, que presenta un sustrato teórico que subyace a otros artículos del volumen, Irene Jones, de la Universidad Nacional de La Plata, nos retrotrae al siglo XIX -y de este modo inaugura una sección de tres artículos concentrados en autoras y corpus de finales del siglo XIX y comienzos del $\mathrm{XX}$ - y se detiene en las figuraciones de la ausencia en "As viúdas dos vivos e as viúdas dos mortos", parte del libro Follas novas, de Rosalía de Castro. De este modo, procede a indagar otro cruce atlántico a partir de uno de los primeros textos poéticos en tratar los alcances de la emigración -concretamente de la emigración gallega, de notoria masividad- y sus efectos en la mujer campesina del siglo XIX. A partir de una selección de poemas que atienden temáticas de extrañamiento, vacío y desarraigo, la joven investigadora trabaja las representaciones de la ausencia de los hombres y el empleo de la voz de la viuda en tanto mecanismo que desarticula una percepción de la fragilidad femenina. La especificidad del enfoque permite un abordaje de esas figuras de mujeres signadas por diferentes tipos de soledad y abandono que las potencian como portavoces del descontento social. A partir del reconocimiento de algunos enclaves seleccionados de la crítica rosaliana, la propuesta explora uno de esos clásicos susceptibles de renovadas y distanciadas lecturas. Desde un margen del margen, una periferia -Galiciaque será revisitada en otros artículos, ofrece un enclave que reúne 
problemáticas compartidas por otros sujetos literaturizados en torno a cuestiones de diáspora y roles femeninos.

La migración de las mujeres reaparece en el artículo de Daniel González Gallego, de la Universidad de Córdoba, quien a su vez también despliega, como Cárcamo, en primer término la problematización de una conceptualización teórica de lo transoceánico, y lo hace teniendo como punto de referencia las redes de solidaridad femenina que potenciaron la interacción entre España y América. González Gallego se dedica al caso concreto de Asturias y atiende desplazamientos signados por el crecimiento de la emigración femenina en los siglos XIX y XX. Junto a una línea que es la de la consideración de esos vínculos englobados por el concepto de "sororidad", explora los términos macro de "hispanismo", "latinoamericanismo" e “iberoamericanismo", y se plantea el objetivo de deconstruir, desde la amplitud de la perspectiva transoceánica, el ya franqueado límite entre lo peninsular y lo americano para encarar una lectura iberoamericanista de la mujer de letras. Esto lo observa tanto en materia de producción escrita como en los contextos sociales y culturales en los que se produjo una inmersión personal y profesional. Al abocarse a los casos de Eva Canel y María Luisa Castellanos, contempla lo que significó la travesía transatlántica en la configuración de una nueva subjetividad femenina, reconstruida a partir de la alteridad dada por el tránsito de uno a otro hemisferio. Es interesante que no solo se registra y analiza comparativamente los aspectos positivos de un accionar social y cultural de esas mujeres, sino que se procede también al señalamiento de rasgos de ambivalencia e incluso de conservadurismo, como la concepción de una idea de hermandad entre España y América que emplee como argumento la lengua común.

En consonancia con el artículo anterior, en la órbita del entresiglos decimonónico pero con fundamental detenimiento en los primeros años del siglo XX, Marta B. Ferrari, de la Universidad Nacional de Mar del Plata, aborda la figura de Concepción Gimeno como protagonista privilegiada de un contexto en el que los vínculos entre España y Argentina fueron centrales en la política de sendos países. Pero, si bien subyace una posible retroalimentación mutua, 
sobresale la percepción de cómo la España moderna ha tenido un determinante impulso en América y, particularmente, en Argentina. La importancia del país caracterizado por la propia Concepción Gimeno como lugar de adopción converge con la consideración del Álbum Ibero-Americano como la publicación tenida en cuenta con especial dedicación para el caso. A su vez el artículo de Ferrari invita a reflexionar sobre una paradójica falta de reconocimiento que la singular mujer que constituye su objeto de estudio ha sufrido a uno y otro lado del Atlántico, situación que llega a manifestarse en el vacío en ámbitos civiles que han agudizado un lamentable grado de invisibilidad.

A continuación, en un tramo del monográfico que apunta a otras convergencias transhemisféricas que se producen en años posteriores a los de las tres contribuciones anteriores, vuelven a aparecer la Guerra Civil española y sus corolarios en la vida y en la obra de las mujeres, por lo cual se retoma una línea sembrada desde la primera contribución a esta Baza de textos.

Paula Simón, de la Universidad Nacional de Cuyo, analiza textos que remiten a la experiencia concentracionaria atravesada por tres mujeres españolas republicanas: Silvia Mistral, Cristina Martín y Mada Carreño. El contexto de los testimonios, dado por el paso por centros de acogida y refugios del sur de Francia, presenta lo transhemisférico con la puntualización de sus respectivos exilios en México. A través del análisis de la voz de las supervivientes, la investigadora retoma un área de estudios que domina desde hace varios años y plantea -revisando sus propios avances en otra instancia de investigación- un mecanismo que comprende situaciones de sanción y desplazamiento sufridas por estas mujeres una vez finalizada la Guerra Civil española. Conjuntamente, el trabajo permite reconocer cómo México se transformó para estas mujeres -aún a contrapelo de limitaciones y expectativas vinculadas a cuestiones de género- en ámbito apto para el desarrollo de un desempeño en el que la escritura y la edición, desde otro hemisferio, de algún modo reconvirtieron la traumática experiencia del paso por el sistema de reclusión francés en la inmediata posguerra. 
En el segundo artículo de este tramo de estudios centrados en derredor de la Guerra Civil española y sus impactos directos, Daniela Serber, de la Universidad del Salvador, se vuelca a analizar el estreno, en Buenos Aires, de la obra de teatro Un hombre y su vida, de Salvadora Medina Onrubia. La singular, atractiva y excéntrica figura de Medina Onrubia no es leída desde un encuadre biografista -interesantísima posibilidad, sin duda, pero que ha sido realizada en otros formatos y soportes. Queda claro en esta perspectiva que Serber no pretende, por tanto, reponer un caudal de informaciones sobre la periodista y escritora argentina, ni sobre su desempeño como militante anarquista y feminista, entre otros perfiles viables. Se expone, en cambio -con especificidad y a la vez con pasajes referidos a la obra que dejan entrever destellos de esos y otros perfiles, e incentivan también otras líneas de análisisun pormenorizado recorrido por la recepción del estreno de la obra de teatro de una autora argentina sobre la Guerra Civil española en los días anteriores a que sobreviniera la derrota republicana. El objeto de estudio para rastrear esa recepción es la prensa, a través de las reseñas incluidas en periódicos de distintas ideologías, con una cuidadosa selección y reproducción de imágenes de esas publicaciones periódicas.

Toma también como objeto de estudio la prensa de publicación periódica el artículo de Federico Funes, de la Universidad de Buenos Aires, y su recorte temporal y enfoque en una determinada autora están motivados, asimismo, por la Guerra Civil española, sus derivaciones y un ámbito de escritura, circulación y difusión transhemisféricos: España Republicana, órgano de prensa del Centro Republicano Español de Buenos Aires, y concretamente los artículos que María Teresa León difundió allí durante 1941 y 1942. El joven investigador explora una publicación poco estudiada, de inestimables vínculos transhemisféricos, y que permite, a través del recorte establecido, contemplar una instancia de autoría de María Teresa León en lo que respecta a la mujer en distintos desempeños y vivencias en el contexto de una coyuntura histórica extrema. Si bien el foco principal está puesto en los materiales de prensa antes mencionados, que han implicado un rastrillaje puntual, no se deja de lado el conocimiento de otras zonas de la obra de esta autora, que tal como la autora 
considerada en el artículo anterior, es sumamente multifacética y aún susceptible de mucho más estudio en lo que respecta a variadas materialidades de expresión.

Por su parte, Dolores Fernández Martínez, de la Universidad Complutense de Madrid, suma una aportación que, a pesar de que no se circunscribe a una escritora, incorpora a otra representante ineludible de las mujeres del exilio español transatlántico y transhemisférico: Maruja Mallo. A partir del reconocimiento de que la pintora ha sido considerada desde una perspectiva biográfica en abordajes puntuales centrados en un recorrido vital, Fernández Martínez se dedica a las obras realizadas entre España y Argentina, y entre años clave: 1936 y 1939. Fundamentalmente se aboca a Sorpresa del trigo y Canto de las espigas, que será parte de la serie La religión del trabajo, pintada en Argentina con dibujos y apuntes realizados en su tierra natal, Galicia, poco antes de su exilio tras el estallido de la Guerra Civil española. Con una simbología que, como la propia Mallo, tiende un puente entre dos orillas y entre años clave, esta aproximación, llevada a cabo desde un punto de vista pictórico y conceptual, explora otros factores de recepción en el país de acogida, con una mirada divergente pero pasible de complementariedad con el artículo anterior, y trae a cuento un diálogo revisitado en cuanto a los vínculos transhemisféricos de Galicia en su particular enclave atlántico. Este artículo, entonces, franquea el pasaje al tramo final de la sección Baza de textos del monográfico, donde diferentes aspectos de la movilidad de mujeres entre Galicia y América Latina vuelven a ser eje de análisis.

Diego Rivadulla Costa, de la Universidade da Coruña, indaga en una fracción del sistema literario gallego en la que ha proliferado la narrativa de la memoria de autoría femenina. Con conocimiento de una complejización del subgénero, en detrimento de algunos posicionamientos críticos que siguen mirando con desconfianza los temas de memoria, el investigador da cuenta de un creciente advenimiento de relativamente jóvenes pero ya reconocidas autoras, entre las que selecciona a Rosa Aneiros. Por constituir un ejemplo representativo del tratamiento de la emigración y el exilio en Cuba, Rivadulla Costa se concentra en la novela Sol de Inverno, pero su lectura se imbrica en 
una trama más amplia de recuperación de la memoria y de homenaje a quienes padecieron ese tipo de desarraigos. Esta mirada se conecta, sin superposición ni reiteraciones sino como en una lógica continuidad con el artículo siguiente, de Lucila Lastero, de la Universidad Nacional de La Plata, con el que finaliza la sección de Baza de textos. La cuestión migratoria, que ya había emergido en los primeros artículos, es considerada por Lastero sobre la base de una interesante noción de vaivén, es decir, de un movimiento que no se agota en tener en cuenta una sola trayectoria sino una variable no poco habitual de posibles -pero oblicuos, en ocasiones traumáticos e incompletosregresos entre España y América Latina. Las novelas en las que se escoge analizar esto son Finisterre y Solo queda saltar, de María Rosa Lojo, y la situación de mujeres que enfrentan una doble pertenencia cultural, marcada por España y América Latina, resulta un vector de convergencia. Lastero observa los mecanismos simbólicos que dan cuenta de una identidad fluctuante en cada una de las novelas mencionadas e indaga la posibilidad de una síntesis conciliatoria a través de la idea de "vaivén identitario".

Luego de este último artículo, el monográfico se completa y complementa con las secciones Pretextos para el debate y Sobretextos: Reseñas. Tanto una como otra han sido planificadas en función del eje Mujeres 'transhemisféricas'.

En Pretextos para el debate se publica una entrevista, realizada por la investigadora argentina Victoria Torres, residente en Alemania, a la escritora colombiana Consuelo Triviño Anzola, residente desde hace más de tres décadas en España. Surgen en este diálogo aspectos nodales de la experiencia de Triviño. En relación con esta autora, cuya primera novela, Prohibido salir a la calle, es considerada por la crítica como una de las más importantes de la literatura colombiana contemporánea, se toma nota de su raigambre de ensayista, cuentista, narradora, periodista cultural, pero también de su formación académica. La inicialmente compleja relación con la norma lingüística peninsular, la dificultad para compaginar su vocación de escritora con la independencia económica y la referencia a los tiempos de postergación de la escritura desembocan en un esencial detenimiento en su novela Diablotexto Digital 8 (2020), 1-13 
Transterrados, de 2018, un texto sobre la inmigración latinoamericana en España, cuyo punto de partida es una nota de prensa sobre el asesinato de una mujer, y por esta vía se introduce una perspectiva no perceptible más que fugazmente en las otras secciones del monográfico: la cuestión tan conocida pero tan poco tratada en la ficción -tal como señala Torres- de la inmigración latinoamericana en España. La problematización sobre por qué, tras más de treinta años de vivir en España, las ficciones de la entrevistada no terminaban de arraigar, en su formulación, en esta tierra, aparece como un necesario disparador para una reflexión que pone en tensión la tranquilidad con la que pudo entregarse al oficio y la literaturización de temas incómodos, espinosos, que han motivado una recepción nada unívoca y, por ello, pasible de enriquecer cuestiones aún desatendidas y para las que la literatura es un canal más que considerable.

En la sección Sobretextos: Reseñas se destaca que cuatro de los ocho textos, han sido seleccionados en función del monográfico, y versan sobre libros publicados durante los dos últimos años: Transterradas. El exilio infantil y juvenil como lugar de memoria, de Marisa González de Oleaga, Carolina Meloni González y Carola Saiegh Dorín; Austroatlántica, de Lola Rontano; Aurelia quiere oír, de María Rosa Iglesias y Solo queda saltar, de María Rosa Lojo, reseñados respectivamente por Andrea Cobas Carral, Micaela Fernández Darriba, Claudia López Barros (las tres de la Universidad de Buenos Aires) y Fabiola Mancilla Pinda (de la Universidad Nacional de la Patagonia Austral). En un ítem como el de las reseñas, que ha dejado -injustamente, a mi entenderde ser lo suficientemente reconocido, al menos en los dominios de las calificaciones del ámbito académico, es de agradecer la colaboración de fundamentadas y atentas lecturas que pueden ser un puente para otros acercamientos críticos, habiendo incluso en un caso una adyacencia con una novela considerada en el artículo final de Baza de textos, sin que esto implique reduplicación en sendos tipos de acercamiento desarrollados.

Una de las reseñadoras, Claudia López Barros, fue además quien cedió la fotografía que ilustra la portada del monográfico, esa polivalente mirada hacia el Atlántico que no obtura interpretaciones. La mirada que desborda el 
muro podría haber sido elaborada desde diversos puntos de observación; pero el hecho de que la fotografía esté tomada desde la Torre de Hércules, en A Coruña -sitio lindante con historias de represión y encierro-, dota de más relevancia el campo visual de un espacio abierto, con una literal y a la vez disruptiva transparencia, formas femeninas y perspectiva atlántica.

Por último, si bien no constituye un condicionamiento exclusivo de este monográfico ni de las disciplinas de quienes en él participan, y a sabiendas del evidente carácter global de la situación, resultaría incompleta esta presentación si no incluyera una referencia al complejo contexto en el que fue gestado el volumen. En circunstancias tan anómalas como las que ha interpuesto la pandemia por COVID-19, es importante destacar la dedicación que desde los diferentes roles intervinientes se ha desarrollado. Por tanto, si bien no se estila destinar un párrafo a este tipo de señalamientos en una publicación de carácter académico, para quienes nos hemos abocado a las ciencias humanas y sociales no está de más procurar no perder de vista esos ámbitos de incumbencia que trascienden -o en ocasiones acompañan- los contenidos de investigación y análisis. En ese sentido, y lejos de esbozar una suerte de captatio benevolentiae, es pertinente subrayar que si este monográfico resultó viable y logró constituirse con cohesión y en sintonía con el eje de la convocatoria inicial, fue gracias a que fundamentalmente las autoras y los autores, así como las autoridades de la publicación, muy especialmente su secretaria, Luz C. Souto, y las distintas voces involucradas en el trabajoso proceso de una publicación como Diablotexto Digital, desafiaron estos tiempos de incertidumbre y complicaciones transversales. Excede el alcance de estas líneas y de las disciplinas académicas atinentes a los enfoques del volumen determinar si algunas de las problematizaciones de circunstancias específicamente atravesadas por mujeres estuvieron también orbitando en la trastienda de las investigaciones y de los análisis aquí reunidos. Iría asimismo a contramano del registro esperado abundar en todo detalle que se inmiscuyera en la cotidianidad de elaboraciones articuladas en ámbitos domésticos y en tiempos de distancia obligada; pero sería sesgado ignorar el 
notable esfuerzo para procurar, en algunos enfoques en particular, el acceso a los materiales en circunstancias de aislamiento social, con una alteración del tiempo que potenció desigualdades varias, entre ellas, desigualdades de género.

Sin duda, algunos de los aspectos aquí estudiados no se circunscriben a la letras referidas a una autora, un tema y una obra puntual, y si por un lado poseen la especificidad del detenimiento en un objeto de estudio, por otro lado -y de manera más acentuada en un contexto de concreción como el que han tenido- invitan a reflexionar de un modo más amplio acerca de invisibilidades, obstáculos, marginaciones, olvidos, esquinados reconocimientos, preconceptos y naturalizaciones acerca de las cuales echa luz el acercamiento a estas mujeres "transhemisféricas".

\section{BIBLIOGRAFÍA}

Enjuto-Rangel, Cecilia; Faber, Sebastiaan; García-Caro, Pedro; Newcomb, Robert Patrick (eds.) (2019). Transatlantic Studies. Latin America, Iberia, and Africa. Liverpool: Liverpool University Press.

FABER, Sebastiaan (2008). "Fantasmas hispanistas y otros retos transatlánticos". En Mabel Moraña (ed.), Cultura y cambio social en América Latina. Madrid/Frankfurt: Iberoamericana/Vervuert, pp. 315-345.

Gallego Cuiñas, Ana (2012). Entre la Argentina y España. El espacio transatlántico de la narrativa actual. Madrid/Frankfurt: Iberoamericana/Vervuert.

GaRcíA GaliNDO, Juan Antonio (2014). "Estudios transatlánticos: En torno a un proyecto académico universitario". Revista Surco Sur, vol. 4, issue 6, pp. 61-64.

MAcclucl, Raquel (2019). “Transatlántica y transhemisférica. La literatura española contemporánea como campo de conocimiento y área disciplinar". En prensa. En Actas de las Jornadas de Jóvenes Hispanistas: Facultad de Filosofía y Letras: Universidad de Buenos Aires.

MACCIUCI, Raquel (2018). "El hispanismo y la literatura española en el ámbito académico latinoamericano. Una visión desde Argentina". En Rike Bolte, Jenny Haase y Susanne Schlünder (eds.), La Hispanística y los desafíos de la globalización en el siglo XXI. Posiciones, negociaciones y códigos en las redes transatlánticas. Madrid/Frankfurt: Iberoamericana/Vervuert, pp. 113-130.

Macciucl, Raquel (2006). Final de Plata Amargo. De la vanguardia al exilio: 
Ramón Gómez de la Serna, Francisco Ayala, Rafael Alberti. La Plata: Ediciones Al Margen.

MARTíneZ, Erika (ed.) (2019). Señales mutuas. Estudios transatlánticos de literatura española y mexicana hoy. Madrid/Frankfurt: Iberoamericana/Vervuert.

ORTEGA, Julio (ed.) (2010). Nuevos hispanismos interdisciplinarios $y$ transatlánticos. Madrid/Frankfurt: Iberoamericana/Vervuert.

TRIGO, Abril (2012). "Los estudios transatlánticos y la geopolítica del neohispanismo", Cuadernos de literatura (enero-junio de 2012), n. ${ }^{\circ} 31$, pp. 16-45. 